\title{
Formação de professores pela pesquisa no Estágio Supervisionado: a compreensão do ambiente a partir da alimentação escolar
}

\author{
Teacher training through the Supervised Internship: understanding the environment \\ from school feeding
}

Formación de profesores por la investigación en la Etapa Supervisada: la comprensión del ambiente a partir de la alimentación escolar

Augusto Antonio de Paula

Discente em Ciências Biológicas, UFLA, Brasil augustodiipaula@gmail.com

Ricardo Campos Queixas

Mestrando, UFLA, Brasil ricardo.queixas@estudante.ufla.br

\section{Marina Battistetti Festozo}

Professora Doutora, UFLA, Brasil marina.festozo@ufla.br 


\section{RESUMO}

O presente trabalho tem o objetivo de avaliar os processos educativos desenvolvidos por uma etapa do estágio supervisionado no processo de formação inicial de professores que busca possibilitar a compreensão das relações que a escola estabelece com o ambiente do seu entorno bem como com a sua comunidade. $O$ estágio supervisionado se propôs, a partir da Educação Ambiental Crítica, a compreender o ambiente por meio da alimentação escolar, levando em conta as relações sociais, políticas, econômicas e ambientais da produção, distribuição e consumo dos alimentos. Para essa compreensão, foi realizada uma pesquisa, de construção coletiva com os licenciandos. Ao final do semestre letivo, foi pedido aos discentes que respondessem um questionário avaliando as atividades desenvolvidas durante o período em seu processo de formação docente. Esse questionário foi utilizado para a análise do trabalho, que foi baseada na abordagem qualitativa de pesquisa e análise de conteúdo. A partir das respostas dos estagiários, foram encontradas três categorias, que são: "importância da regência de aulas", "educação ambiental e soberania alimentar" e "professor-pesquisador e a formação docente". Após a análise e discussão foi possível perceber a influência das atividades do estágio no processo de formação inicial de professores, em que houve auxílio aos processos de formação da identidade docente e superação da dicotomia entre teoria e prática, deixando evidente que atividades como essa podem ser replicadas a fim de contribuir para a formação crítica de professores e educadores ambientais.

PALAVRAS-CHAVE: Estágio supervisionado. Educação ambiental crítica. Formação de professores.

\section{ABSTRACT}

The present study has the objective of evaluating the educational processes developed by a stage of the supervised internship in the process of initial teacher training that seeks to make possible the understanding of the relationships that the school establishes with the environment of its surroundings as well as with its community. The supervised internship proposed, based on Critical Environmental Education, to understand the environment through school feeding, taking into account the social, political, economic and environmental relations of food production, distribution and consumption. For this understanding, a research was carried out, of collective construction with the undergraduates. At the end of the semester, students were asked to answer a questionnaire evaluating the activities developed during the period in their teacher training process. This questionnaire was used to analyze the work. For the analysis, the qualitative research method and content analysis were used, where three catefories were found: "importance of classroom management", "environmental education and food sovereignty" and "teacher-researcher and teacher training". After the analysis and discussion, it was possible to perceive the influence of the activities of the internship in the process of initial teacher training, in which the processes of teacher identity formation were overcome and the dichotomy between theory and practice was overcome, making it clear that activities like this can be replicated in order to contribute to the critical training of teachers and environmental educators.

KEYWORDS: Supervised internship. Critical environmental education. Teacher training.

\section{RESUMEN}

El presente trabajo tiene el objetivo de evaluar los procesos educativos desarrollados por una etapa de la etapa supervisada en el proceso de formación inicial de profesores que busca posibilitar la comprensión de las relaciones que la escuela establece con el ambiente de su entorno así como con su comunidad. La etapa supervisada se propuso, a partir de la Educación Ambiental Crítica, a comprender el ambiente a través de la alimentación escolar, teniendo en cuenta las relaciones sociales, políticas, económicas y ambientales de la producción, distribución y consumo de los alimentos. Para esa comprensión, se realizó una investigación, de construcción colectiva con los licenciandos. Al final del semestre lectivo, se pidió a los alumnos que respondieran un cuestionario evaluando las actividades desarrolladas durante el periodo en su proceso de formación docente. Este cuestionario fue utilizado para el análisis del trabajo, que se basó en el abordaje cualitativo de investigación y análisis de contenido. A partir de las respuestas de los pasantes, se encontraron tres categorías, que son: "importancia de la regencia de clases", "educación ambiental y soberanía alimentaria" y "profesor-investigador y la formación docente". Después del análisis y discusión fue posible percibir la influencia de las actividades del estadio en el proceso de formación inicial de profesores, en que hubo ayuda a los procesos de formación de la identidad docente y superación de la dicotomía entre teoría y práctica, dejando evidente que actividades como ésta pueden ser replicadas para contribuir a la formación crítica de profesores y educadores ambientales.

PALABRAS CLAVE: Etapa supervisada. Educación ambiental crítica. Formación de profesores. 


\section{INTRODUÇÃO}

O estágio docente constitui-se como algo que está além da aquisição de técnicas, pois, assim como afirmam Pimenta e Lima (2005), integra uma área de conhecimento e, portanto, rompe com a ideia de atividade prática instrumental. As autoras ainda dizem que é neste momento que há maior interação entre os cursos de formação docente com o campo social, em que há o desenvolvimento de suas práticas educativas. Dessa forma, "considerar o estágio como campo de conhecimento significa atribuir-lhe um estatuto epistemológico que supere sua tradicional redução à atividade prática instrumental" (PIMENTA e LIMA, 2004, p.29). No entanto, o estágio é visto em muitos cursos de formação inicial de professores como uma atividade meramente técnica, com isso, assim como apontado por Pimenta e Lima (2005), os licenciandos muitas vezes não se aproximam suficientemente da vida e do trabalho que é desenvolvido nas escolas, já que as disciplinas que compõe a matriz curricular dos cursos de formação tem dificuldades em estabelecer ligações entre o que foi aprendido e a realidade do processo educativo.

Nessa perspectiva, o estágio é reduzido à simples observações dos professores sem uma reflexão crítica com fundamentos teóricos, sendo possível inferir que se a formação inicial de professores mantiver sua estrutura, onde os licenciandos não são formados com um viés crítico e reflexivo, sempre haverá a imitação desse modelo de professores, que, muitas vezes, não possuem os elementos necessários à prática docente, como um olhar crítico acerca da educação tradicional presente de forma majoritária nas escolas do país. Pimenta e Lima (2005) ressaltam que este modelo da imitação parte do pressuposto que a realidade do processo educativo nunca muda, assim, como os alunos que frequentam a escola, e a própria realidade social.

O estágio supervisionado é um processo de aprendizagem importante aos profissionais que desejam estar preparados para enfrentar os desafios da carreira docente, pois permite aos futuros educadores a construção de elementos, a partir de observações e regências de aulas, além de pesquisas e projetos, fundamentais à prática docente, além de possibilitar a aproximação com a escola e os atores que compõem a comunidade escolar, configurando-se como uma das etapas de maior relevância na vida acadêmica dos alunos de licenciatura (TARDIF, 2002). Para Pimenta (2012), é a partir desse momento que os licenciandos se enxergarão como futuros professores, já que terão que encarar o desafio de conviver, falar e ouvir com linguagens e saberes distintos do seu meio.

Diante disso, Corte e Lemke (2015) ressaltam que o ato de formar professores não deve se reduzir no treinamento de diferentes formas e técnicas de ensinar determinados conteúdos. Para as autoras, formar profissionais da educação exige o desenvolvimento de práticas de análise, de reflexão e de compreensão do que seja verdadeiramente atuar no contexto escolar nos dias de hoje (CORTE e LEMKE, 2015, p. 31006). Dessa forma, conseguirão atuar no auxílio à formação de seus educandos em uma perspectiva crítica e reflexiva. No entanto, isso só é possível a partir de uma visão de sociedade em sua totalidade, onde são discutidas as relações sociais no e com o ambiente em seus diferentes âmbitos. 
Pensando nessas questões, uma das etapas do Estágio Supervisionado, obrigatório no curso Ciências Biológicas de uma Universidade Federal localizada no Sul de Minas, buscou contemplar a Educação Ambiental (EA) Crítica no processo de formação docente.

Essa vertente de EA, que é uma práxis social, tem como objetivo a formação de sujeitos emancipados, que se dá a partir da compreensão da realidade de forma holística e crítica (LOUREIRO e TOZONI-REIS, 2007). Nessa perspectiva, para Trein (2012), a EA pode contribuir com a construção de outro projeto civilizatório, através da compreensão histórica das contradições da sociedade capitalista, possibilitando, portanto, a busca pela sua superação. Assim como afirma a autora, sob esta lógica a humanidade passa a explorar os recursos naturais de forma desenfreada a partir do desenvolvimento das relações sociais, políticas e econômicas, sem que haja uma preocupação com os impactos causados no ambiente e na própria humanidade, as pessoas menos favorecidas.

Diante disso, o processo educativo deve ser pensado para quebrar "o conceito enraizado de ambiente que não considera seu caráter social e histórico, não se resumindo apenas a concepção biológica" (CASTRO; OLIVEIRA; FESTOZO, 2018, p. 1260). No entanto, a EA crítica não é a salvação dos problemas educacionais do país, é preciso buscar entender as questões que envolvem tais problemas. Para Meyer (1991), a educação do país está descaracterizada, pois é dada maior ênfase à memorização de conteúdos e fórmulas, as condições do trabalho docente estão precarizadas e há uma desvinculação da educação com a realidade socioeconômica do país. Sendo assim, é necessário repensar o espaço escolar, de maneira que contribua para a observação e compreensão dos estudantes acerca da EA como uma forma de pensar propostas de mudança no processo de formação humana, no processo de humanização, visando à transformação do projeto de sociedade que hoje se desenvolve sob a lógica do modelo capitalista. Nessa perspectiva, o ambiente considerado como espaço construído inclui o mundo natural, mas não como realidade autônoma, independente, sem sujeito social (MEYER, 1991).

Diante dessas problemáticas, as atividades do estágio supervisionado se propuseram a estabelecer um diálogo com a questão da alimentação escolar na tentativa de compreender o ambiente escolar na relação com o ambiente de seu entorno - incluindo as pessoas que o compõe -, pois, de acordo com Festozo e Michelini (2017, p. 8) "a forma como o sistema alimentar está organizado atualmente reflete a organização da sociedade mundial predominantemente regida pelo sistema econômico capitalista, cujos princípios promovem a desigualdade social e a degradação ambiental". As autoras ressaltam que a produção e comercialização de alimentos se inserem nessa lógica capitalista e, portanto, são qualificados como mais uma mercadoria e que, nesta mesma lógica, "a garantia da segurança alimentar de todos os povos está atrelada a processos em que alimento, energia, saúde, ambiente, tecnologia e lucratividade estabelecem relações complexas e multifacetadas, tanto em nível nacional como global" (FESTOZO e MICHELINI, 2017, p.2). Ao abordar tais questões, as atividades propostas pelo estágio supervisionado podem possibilitar aos licenciandos a ampliação da visão acerca do ambiente, permitindo maior compreensão da realidade onde se situam. 


\section{OBJETIVOS}

O presente trabalho tem o objetivo de avaliar os processos educativos desenvolvidos por uma etapa do estágio supervisionado no processo de formação inicial de professores que busca possibilitar a compreensão das relações que a escola estabelece com o ambiente do seu entorno bem como com a sua comunidade.

\section{METODOLOGIA}

O estágio supervisionado compõe a matriz curricular obrigatória do curso de licenciatura em uma Universidade Federal localizada no Sul de Minas, sendo ofertado no sétimo período de graduação. Tem o objetivo de auxiliar na formação da identidade docente, inserindo os licenciandos em discussões acerca do contexto da educação e do ensino de ciências. As atividades do estágio são divididas em duas etapas: presença dos licenciandos nas escolas por meio de observações e regências de aulas, desenvolvimento de projetos e convívio com a comunidade escolar, sempre orientados por uma visão reflexiva dessas práticas. Ainda, há encontros semanais na Universidade, em que se discute as questões relacionadas às escolas, possibilitando maior entendimento da realidade escolar, na busca pela compreensão do ambiente, é nesse momento que há discussões, como: as relações entre Universidade, escola e comunidade e reflexões sobre o estágio supervisionado.

Nesta etapa de formação, foi proposta a construção de uma pesquisa coletiva, almejando proporcionar situações e momentos em que os licenciandos pudessem se desenvolver enquanto pesquisadores na área da educação, ao mesmo tempo em que buscávamos compreender o ambiente escolar em sua totalidade, as relações sociais, econômicas, políticas e culturais que influenciavam o cotidiano escolar, tendo como eixo central a EA Crítica. No trabalho em questão a pesquisa realizada buscou entender como a alimentação pode contribuir para o processo de compreensão do ambiente de forma holística. A partir da construção de um questionário pelos licenciandos, buscou-se tal compreensão. A pesquisa foi realizada em seis Escolas Estaduais da cidade Lavras-MG, locais onde havia estagiários desta turma. Abaixo estão as perguntas construídas:

1 - De onde vêm os alimentos consumidos na sua casa e na escola? (Pergunta feita aos educandos)

2 - De onde vêm os alimentos consumidos na escola? (Pergunta feita às cantineiras)

3 - Como é calculada a quantidade de alimento para ser servido? Os educandos costumam repetir? (Pergunta feita às cantineiras)

4 - Como é definido o cardápio escolar? (Pergunta feita à direção e às cantineiras)

5 - Há problemas com a alimentação escolar? (Desperdício de alimentos) (Pergunta feita a toda comunidade escolar)

6 - A alimentação é abordada no currículo escolar? (Pergunta feita aos docentes)

7 - Como é feita a comunicação entre a escola e os agricultores familiares? (Pergunta feita à direção) 
A partir da obtenção das respostas, cuja análise ocorrerá em outro trabalho, foi possível constatar que o processo alimentar e de que aquisição destes alimentos dentro das escolas públicas é muito mais complexo do que se imaginava, onde nem mesmo quem está em constante contato com estes processos tem conhecimento da origem dos alimentos utilizados na merenda escolar. Esta constatação nos traz uma nova reflexão: a compreensão dos processos de produção dos alimentos é possibilitada à população de forma geral? E os demais processos de produção da vida, dos bens materiais e imateriais da humanidade, são de conhecimento dos próprios trabalhadores, diretamente relacionados com esta cadeia produtiva? Estas questões parecem estar intimamente ligadas com o processo de alienação do trabalho, que dificulta a compreensão complexa e completa das diferentes etapas e ciclos de produção e reprodução da vida, especificamente relacionado ao nosso objeto de estudo, o mesmo parece ocorrer com os processos que envolvem a alimentação desde sua origem até o preparo da refeição na escola.

Ao final das atividades do estágio foi pedido aos licenciandos para responderem um questionário, onde avaliavam as atividades para a sua formação e para formação inicial de professores. Esse questionário foi utilizado para a análise do presente trabalho. Segue abaixo:

1 - O que a experiência do estágio the ensinou, considerando a vivência na escola e as discussões coletivas na Universidade?

2 - A alimentação escolar pôde contribuir para compreensão do ambiente escolar e da relação escola - comunidade? De que forma?

3 - Você tem sugestões de desenvolvimento de atividades/projetos a partir dos estudos e análises deste semestre?

4 - Avalie o estágio, a partir de sua vivência, das pesquisas realizadas e de nossas reuniões, indicando pontos positivos e pontos a melhorar.

A análise dos dados utilizou-se da abordagem qualitativa, através da análise de conteúdo das respostas dos estudantes do Estágio Supervisionado ao questionário com questões abertas. De acordo com Tozoni-Reis (2007), a pesquisa em educação possui essência qualitativa, contudo "sem perder o rigor metodológico e a busca por compreender os diversos elementos dos fenômenos estudados" (IDEM, p.10).

A escolha do instrumento de coleta de dados com questões abertas se deu, pois tal questionário possibilita ao sujeito "elaborar as respostas, com suas próprias palavras, a partir de sua elaboração pessoal” (SEVERINO, 2007, p. 126).

\section{RESULTADOS E DISCUSSÃO}

A partir da análise das respostas ao questionário, foram encontradas três categorias. Abaixo segue o quadro com as categorias e a descrição. 
Quadro 1: Categorias e descrição das categorias

\begin{tabular}{|c|c|}
\hline Categorias & Descrição das categorias \\
\hline Importância da regência de aulas & $\begin{array}{l}\text { Aqui, os relatos destacam a importância das regências de } \\
\text { aulas no estágio seguidas de discussões na universidade } \\
\text { como prática reflexiva. }\end{array}$ \\
\hline Educação Ambiental e a Soberania Alimentar & $\begin{array}{l}\text { Nesta categoria, as falas apontam o processo de } \\
\text { compreensão do ambiente a partir da questão alimentar. }\end{array}$ \\
\hline Professor-pesquisador e a formação docente & $\begin{array}{c}\text { As avaliações desta categoria evidenciam o processo } \\
\text { formativo proporcionado pela pesquisa durante as } \\
\text { atividades do estágio. }\end{array}$ \\
\hline
\end{tabular}

Fonte: Autoral, 2019

Na primeira categoria é possível observar que os graduandos destacaram a importância das regências de aulas no processo formativo, e, para além disso, salientaram a relevância da discussão dessas práticas durante os encontros na universidade. A discussão posterior às aulas ministradas permite que haja uma reflexão acerca da prática docente, possibilitando aos futuros professores a construção de um olhar crítico para os processos pedagógicos envolvidos no ato de reger aulas. Nessa perspectiva, para Barreiro e Gebran (2006), o estágio supervisionado deve se constituir com base na reflexão e na formação da identidade profissional, proporcionando embates no decorrer de suas atividades e das experiências dos licenciandos.

Scalababrin e Molinari (2013) apontam que ao permitir a realização da prática em sala de aula, o estágio supervisionado se caracteriza como uma oportunidade de romper com a dicotomia existente entre teoria e prática, já que os futuros professores terão que aliar seus saberes pedagógicos e saberes específicos. As autoras ainda afirmam que o estágio possibilita aos discentes a compreensão da realidade da profissão docente. Sendo assim, cabe ao estágio "desenvolver atividades que possibilitem o conhecimento, a análise, a reflexão do trabalho decente, das ações docentes, nas instituições, a fim de compreendê-las em sua historicidade, identificar seus resultados, os impasses que apresenta, as dificuldades" (PIMENTA e LIMA, 2004, p. 55).

Portanto, a prática docente deve ser um elemento de reflexão diário, para que assim as atividades desenvolvidas possam contribuir de maneira significativa no auxílio à formação de educandos que compreendam a realidade social na qual estão inseridos, e, assim, exercer a cidadania de maneira crítica (SCALABRIN e MOLINARI, 2013). Diante disso, as autoras ainda destacam que para que isso aconteça é necessário que o futuro professor entenda a importância do trabalho coletivo na escola em sua formação.

$\mathrm{Na}$ segunda categoria, os licenciandos apontaram a questão da Educação Ambiental e a soberania alimentar como mote para a compreensão do ambiente e mais especificamente do ambiente escolar. Antes de tudo é preciso destacar que a Lei 9.795/99 (BRASIL), regulamentada pelo Decreto 4.281/02 que instituiu a Política Nacional de Educação Ambiental (PNEA), determina que a educação ambiental seja tarefa do Ministério do Meio Ambiente Departamento de Educação Ambiental e do Ministério da Educação - Coordenação Geral de 
Educação Ambiental e deve ocorrer em todos os níveis e modalidades de ensino. No entanto, Tozoni-Reis e Campos (2014) evidenciam que o processo de inserção da educação ambiental na educação básica tem se apresentado de forma conturbada e conflituosa.

O processo educativo, em um movimento dialético, "ao mesmo tempo em que constrói o ser humano como humano, constrói também a realidade na qual ele se objetiva como humano, constrói a humanidade" (TOZONI-REIS e CAMPOS 2014, p. 150). Sendo assim, a escola deve instrumentalizar os educandos para uma prática social transformadora, a partir de uma apropriação crítica e reflexiva. As autoras ainda destacam que, dessa forma, não é a educação que será a responsável pela transformação social, mas os sujeitos, instrumentalizados pelos saberes culturais, que irão criar as condições objetivas para uma prática social transformadora. Assim se caracteriza a EA em sua concepção crítica, contudo, existem outras vertentes que se preocupam com as questões de preservação da natureza, proteção aos animais e a diminuição de lixo, assumindo um caráter naturalista e pouco contextualizado (ADAMS, 2005). Ao não fazer uma crítica mais profunda à sociedade, buscando apenas resolver alguns problemas decorrentes das formas de organização social no e com o ambiente, vertentes como essas contribuem para a manutenção da organização social.

Nesse sentido, Festozo e Michelini (2017) evidenciam que a EA crítica tem o intuito de propor que os problemas ambientais e sociais sejam discutidos de forma holística, em sua materialidade, levando em conta os diversos elementos que compõem suas relações. Assim, entendem que o enfrentamento dos problemas socioambientais não deve ser feito de maneira individual. As autoras ainda destacam que a educação ambiental é um processo contínuo que visa a instrumentalização, teórica e prática, dos sujeitos para a compreensão da realidade, em sua construção histórica e dialética, para que assim possam exercer de forma crítica a cidadania, de modo a transformar a sociedade em direção a um projeto mais justo e igualitário.

Diante disso, para a compreensão do ambiente a partir da alimentação é necessário entender que o Programa Nacional de Alimentação Escolar (PNAE) é uma das mais antigas e permanentes intervenções governamentais federais de suplementação alimentar no âmbito das políticas social e assistencial do Brasil (FERIGOLLO et al, 2017, p. 2). Sendo um dos maiores programas de alimentação escolar do mundo, em 2009 implementa a Lei n 11.947, determinando que no mínimo $30 \%$ do valor repassado aos estados municípios e Distrito Federal pelo Fundo Nacional de Desenvolvimento da Educação (FNDE) sejam empregados para a compra de alimentos da agricultura familiar e do empreendedor rural ou de suas organizações, dando prioridade aos assentamentos da reforma agrária, às comunidades tradicionais indígenas e às comunidades quilombolas.

Para Malaguti (2015) o encontro entre a alimentação escolar e a agricultura familiar tem provocado transformações nas escolas do país, possibilitando que alimentos saudáveis com forte apelo regional, possam ser consumidos diariamente pelos educandos do Brasil. Ainda, Maluf (2006) ressalta que essa aproximação entre a agricultura familiar e a escola gera ganhos pecuniários para ambos, evitando até gastos com transporte.

No entanto, a pesquisa realizada pelos licenciandos nas escolas estaduais da cidade de LavrasMG aponta que a cota de alimentos comprados pelas escolas não chega ao mínimo de $30 \%$ da 
agricultura familiar. Além disso, as relações entre produtores familiares locais e escola têm sido mediadas pela licitação do processo de compra e venda, há pouca ou nenhuma comunicação entre os sujeitos envolvidos, o que tem acarretado em muita dificuldade de entendimento dos problemas entre ambos e, portanto, na quase impossibilidade de estreitamento de laços em busca de uma parceria profícua. Diante disso, ao analisar com maior profundidade a produção, a comercialização de alimentos e a segurança alimentar, ficam evidentes os problemas da lógica de mercado que prioriza "a saúde do sistema financeiro em detrimento da saúde, da cultura, do bem-estar e da própria sobrevivência da população" (FESTOZO e MICHELINI, 2017 p. 2).

Por fim, a última categoria evidencia a questão do professor-pesquisador na formação docente. Os cursos de formação inicial de professores deveriam instrumentalizar os licenciandos de modo que consigam reunir, em suas ações docentes, elementos que os auxiliem no processo da construção da identidade profissional. Sendo assim, é necessário que os futuros professores também sejam pesquisadores, reconhecendo a "importância da pesquisa na formação e no trabalho docente, considerando o papel ativo e crítico do professor como o sujeito investigador" (OLIVEIRA e GONZAGA, 2012, p. 692). Os autores ainda destacam que esse movimento de formação assume um caráter político, social e epistemológico, podendo significar um processo de ressignificação do trabalho docente, produzindo explicações sobre o ensino e a realidade educativa entendida como prática social.

Oliveira e Gonzaga (2012, p. 962) ainda destacam que:

Essa perspectiva de formação defende a possibilidade da pesquisa no desenvolvimento do trabalho pedagógico como instrumento de construção da autonomia do professor, emergindo a partir das múltiplas possibilidades de produção e reconstrução de saberes, gerando mudanças significativas tanto na postura quanto na cultura caracterizadora do processo de construção do conhecimento e da própria identidade do contexto em que a respectiva formação acontece. Em outras palavras, quando mediada pela pesquisa, a formação do professor pode representar estratégia de produção de conhecimento, desenvolvimento profissional e mudança da prática docente, uma vez que, ao se rejeitar a perspectiva de professor como consumidor de conhecimento acadêmico, transmissor e implementador do ensino, reconhece-se a capacidade investigadora tanto da sua prática pedagógica quanto da realidade em que se insere.

Dessa forma, o estágio supervisionado pode ser oportunidade para proporcionar aos licenciandos a elaboração e desenvolvimento de pesquisas, para que consigam fazer uma análise dos contextos nos quais os estágios se realizam. Nessa perspectiva, Pimenta (2012) afirma que o professor deve ser um pesquisador crítico e reflexivo sobre sua atuação, produzindo, a partir dessa pesquisa, uma ação inovadora. Oliveira e Gonzaga (2012, p. 694) acrescentam que o professor deve estar envolvido com a pesquisa por dois motivos: 
"acompanhar o desenvolvimento histórico do conhecimento" e "porque o conhecimento só se realiza como construção de objetos".

Por fim, os autores ainda destacam que o processo investigativo da realidade escolar com bases científicas, desenvolvido pelos estágios, auxilia na formação do "aluno/pesquisador em autor de propostas teóricas, que podem ser avaliadas pelas escolas e por seus pares na academia, a fim de se constituírem em propostas metodológicas para as atividades escolares" (IBIDEM, p. 694).

\section{CONSIDERAÇÕES FINAIS}

A partir da análise e discussão do trabalho, é possível perceber a relevância das atividades do Estágio Supervisionado no processo de formação inicial de professores, de modo que permitiu aos discentes a construção de elementos essenciais à construção da identidade docente e à compreensão do ambiente escolar e sua relação com o entorno. Ainda, o estágio auxiliou na formação de educadores com viés crítico e reflexivo, de modo que possam atuar no auxílio à formação para o exercício crítico da cidadania de seus futuros educandos.

Fica evidente a importância das atividades propostas no processo de compreensão da realidade escolar, e, para além disso, no entendimento das relações de poder estabelecidas e consolidadas pelo modo de produção capitalista, pois permite aos licenciandos compreenderem como o sistema influencia as decisões tomadas no âmbito educacional, ao discutir a questão da EA em uma perspectiva crítica. Logo, a formação de professores críticos, que compreendam a realidade em sua totalidade é essencial para a construção de uma educação emancipatória, que permite aos educandos a participação social de maneira autônoma.

\section{AGRADECIMENTO}

Agradecemos à Coordenação de Aperfeiçoamento de Pessoal de Nível Superior pela bolsa do Programa de Residência Pedagógica concedida a um dos autores deste trabalho e também a todas as escolas Estaduais de Lavras/MG, e seus envolvidos, participantes deste trabalho, sem os quais esta publicação não seria possível.

\section{REFERÊNCIAS BIBLIOGRÁFICAS}

ADAMS, Berenice Gehlen. O que é Educação Ambiental? Publicado no website do Projeto Apoema - Educação Ambiental, 2005. Disponível em: www.apoema.com.br, acessado em 17 de maio de 2019

BRASIL, Política Nacional de Educação Ambiental, Lei 9795. Diário Oficial da República Federativa do Brasil, Brasília, DF, 27 abr. 1999.

Lei no 11.947 de 16 de junho de 2009. Dispõe sobre o atendimento da alimentação escolar e do Programa Dinheiro Direto na Escola aos alunos da educação básica. Diário Oficial da União 2009; 17 jun. 2009

BARREIRO, Iraíde M. de F.; GEBRAN, Raimunda A. Prática de ensino e estágio supervisionado na formação de professores. São Paulo: Ed. Avercamp, 2006. 
CASTRO, Andressa Aparecida; OLIVEIRA, Carolina de Souza; FESTOZO, Marina Battistetti. A importância da educação ambiental crítica para a formação de professores: Um relato de experiência com alunos do Ensino Médio. FóRUM AMBIENTAL DA ALTA PAULISTA, v. 14, p. 69-81, 2018.

CORTE, Anelise C. Dalla; LEMKE, Cibele K. O estágio Supervisionado e sua importância para a formação docente frente aos novos desafios de ensinar. Educere, Brasília, v. 31, n. 3, p. 31002-31010, 2015

FERIGOLLO, Daniele et al. Aquisição de produtos da agricultura familiar para alimentação escolar em municípios do Rio Grande do Sul. Revista de Saúde Pública, v. 51, p. 1-10, 2017.

FESTOZO, Marina Battistetti;, MICHELINI, Janaína. A segurança alimentar sob o olhar da Educação Ambiental Crítica. In: Anais do IX EPEA -Encontro Pesquisa em Educação Ambiental, Juíz de Fora, MG, 2017.

LOUREIRO, Carlos Frederico. Pesquisa-ação participante e educação ambiental: uma abordagem dialética e emancipatória. In: Tozoni-Reis, Marília Freitas de Campos, org. A pesquisa-ação-participativa em educação ambiental: reflexões teóricas/ Organização de Marília Freitas de Campos. - São Paulo, 2007.

MALAGUTI, Jane Mary Albinati. Programa Nacional de Alimentação Escolar (PNAE): desafios para a inclusão dos produtos da Agricultura Familiar na merenda escolar de Itapecerica da Serra - SP. 2015. Dissertação (Mestrado em em Gestão de Políticas e Organizações Públicas), Universidade Federal de Sao Paulo São Paulo.

MALUF, Renato S. Segurança alimentar e fome no Brasil: 10 anos da cúpula mundial de alimentação. Rio de Janeiro: CPDA/URRJ, 2006. (Relatórios técnicos, 2)

MEYER, Mônica Angela de Azevedo. EDUCAÇÃO AMBIENTAL: UMA PROPOSTA PEDAGÓGICA. Em Aberto, Brasília, v. 10, n. 49, jan./mar. 1991

OLIVEIRA, Caroline Barroncas; GONZAGA, Amarildo Menezes. Professor pesquisador - educação científica: o estágio com pesquisa na formação de professores para os anos iniciais. Ciência \& Educação, v. 18, n. 3, p. 689-702, 2012.

PIMENTA, Selma Garrido. 0 estágio na formação de professores: unidade, teoria e prática? 11. Ed. São Paulo: Cortez, 2012

PIMENTA, Selma Garrido.; LIMA, Maria Socorro Lucena. Estágio e docência. 1. ed. São Paulo: Cortez Editora, 2004. v. $1.296 p$.

Estágio e docência: diferentes concepções. In: Congresso Internacional de Formação Continuada e Profissionalização Docente, 2005, Natal. Anais do Congresso Internacional de Formação Continuada e Profissionalização Docente. Natal: UFP, 2005. v. 1. p. 37-44.

SCALABRIN, Izabel Cristina; MOLINARI, Adriana Maria Corder. A importância da prática do estágio supervisionado nas licenciaturas. UNAR, v. 17, n. 1, 2013.

SEVERINO, Antônio Joaquim. Metodologia do trabalho científico. 23. ed. São Paulo: Cortez, 2007.

TARDIF, Maurice. Saberes docentes e formação profissional. Petrópolis: Vozes, 2002.

TOZONI-REIS, Marília Freitas de Campos. Metodologia de Pesquisa Científica. 2. ed. Curitiba: IESDE Brasil S.A, 2007.

TOZONI-REIS, Marília Freitas de Campos; CAMPOS, Luciana Maria Lunardi. Educação ambiental escolar, formação humana e formação de professores: articulações necessárias. Educar em Revista, Curitiba, Brasil, Edição Especial $n$. 3/2014, p. 145-162. Editora UFPR.

TREIN, Eunice Schilling. A educação ambiental crítica: crítica de quê? Revista Contemporânea de Educação, v. 7, n. 14, 2012. 